\title{
The Inspiration of American University's Strategic Planning on Chinese University's Comprehensive Reformation Planning \\ Case Study of Strategic Planning in University of Minnesota and Comprehensive Reformation Planning in Hohai University
}

\author{
Zhen Xu
}

Department of Development and Planning, Hohai University, 1\# Xikang Road, Jiangsu, China

\begin{abstract}
Chinese universities. Through detailed analysis of strategic planning procedures in University of Minnesota, this paper concludes basic methods, experiences and inspirations from American universities' strategic planning. By utilizing these recommended methods, this papers tries to adopt the experiences and inspirations—emphasis on environmental scanning, regulating specialized planning priorities, cooperation among different teams, logical planning process, etc. into guiding Hohai University's comprehensive reformation planning. Through the construction of a logical diagram for Hohai University's comprehensive reformation, the author also shows the integrated and logical planning process and achievements.
\end{abstract}

Keywords — strategic planning, experiences and inspirations, comprehensive reformation, logical diagram

\section{美国大学战略规划的制定对我国高校改革方案编制的 启示}

一以明尼苏达大学战略规划与河海大学综合改革方案为例

徐 臻

河海大学发展规划处, 南京市西康路一号, 江苏, 中国

\begin{abstract}
摘 要 战略管理对中国高校发展意义重大。本文通过对美国明尼苏达大学战略管理过程的较详细的分析, 总结美国高校战略 管理规制定的基本方法和经验启示。尝试将战略管理的过程及经验启示如重视对环境的扫描、立足本校和科学定位、确定具有特色 的规划重点、两条线通力合作、规划过程强调逻辑性等运用于指导河海综合改革方案编制, 并通过构建河海大学综合改革方案逻辑关 系图来展示战略规划的逻辑过程和实施效果。
\end{abstract}

关键词＼cjkstart战略规划 经验启示 综合改革 逻辑关系图

1. 引言

“战略规划” 曾经多用于公司和军事运营领域, 侧重 于通过一种管理协调方式将长远的目标、任务、以及短期 的行动有效结合。自从19世纪80年代《学术规划: 美国高 等教育管理革命》一书出版之后, 美国高校开始思考 “战 略规划” 的概念以及如何将其运用于学术领域 [1]。经过
多年发展，美国高校通过战略规划管理，解决了危机，发 展了教学与科研, 整体提升了学校水平。本文通过对美国 明尼苏达大学战略管理过程的分析, 尝试将其运用于指导 中国高校综合改革方案编制过程中, 并通过河海大学综合 改革方案逻辑关系图来展示战略规划的初步成果。 


\section{2. 对明尼苏达大学战略管理实施过程的分析}

明尼苏达大学（简称明大）始建于 1851 年, 是美国最 具综合性的高等学府之一, 具有优秀的教育和服务社会的 传统, 有很多在美国和国际上享有盛名的学者, 也是世界 一流的本科、研究生教育学府和学术研究机构。

2004年, 明大新上任的校长布鲁宁克斯决定开启学校 新的战略规划, 原因是明尼苏大大学在几年的发展中遇到 了前所未有的困境, 主要有这几方面: 第一: 办学经费上 涨, 政府投入下降。2003年学校削减福利, 员工当街罢 工；2003年著名经济学家普里斯科特 (Edward C. Prescott) 教授离去, 学校痛失诺贝尔经济学奖。第二: 学术水平滑 坡。明尼苏达大学曾经有19名诺贝尔奖金获得者, 而当年 美新排名停滞不前。在这种形势下, 2004年7月, 明大全面 开始战略规划的编制 [2]。

\section{1 战略管理第一步: 环境扫描}

学校对扫描的要求是: 做到全面、系统, 不留死角。 在当年 8 月至 10 月期间, 学校所有部门牵头人提交了 55 份 报告。报告分析了明大发展的宏观环境、竞争环境、财务 环境。报告由领导牵头, 征集全校意见并进行改革动员和 态度调查。环境扫描得出的结论是: 社会经济环境巨变, 公立高校私立化; 学校高水平师资不足, 全球性人才竞争 严峻; 新生质量低、毕业率低; 学校资源短缺与浪费并 存, 要注重开源节流及效果效益 $[2]$ 。

\section{2 战略管理的第二步：确定战略框架}

这一过程主要由学术副校长领导的 16 人小组完成。任 务包括: 分析学校的目标、愿景、使命; 确定战略规划原 则; 明确规划的重点领域。

(1) 明大确定的新的办学目标为: “在十年内, 把明 大建设成世界上最好的三所公立研究型大学之一”。愿景 为: 通过发展知识改进人类状况。使命为: 发展学术和寻 求真理, 通过教育与社会分享知识, 通过应用知识造福本 州、本国与世界。

(2) 学校确定了战略规划的七大原则: 符合大学核心 使命; 质量、产能、影响; 比较优势与独特性; 学术整 合; 需求与资源; 效果与效益; 资源开发。

(3) 明大明确了战略规划的四个领域: 研究、教学、 公众认同、资源与基础设施; 明确了五个重点: 招收、培 养、挑战、毕业杰出的学生; 招聘、指导、回报、保持杰 出的教师; 培育追求卓越、应对变化的组织文化; 开发资 源, 提高资源利用率; 诚实清晰地与所有利益相关者交 流。当年3月，校董事会投票通过这个计划 [2]。

\section{3 战略管理第三步：战略规划制定}

明大的特色是把整个战略规划制定工作分成管理和学 术两个基本方面, 成立了两个战略规划组:一个负责管理, 一个负责学术。大学所有副校长、各主要部门负责人及部 分教师和学生参加了这两个小组。

其中, 管理战略制定小组提出了七个管理建议: 1、 把学校各单位当作整体来建设和管理; 2、追求卓越、致 力服务、持续改进的管理文化; 3 、集中和共享为特色的 管理模式; 4、学习和采用最佳管理工具, 并在全校范围 内推广; 5 、积极的服务意识; 6 、为大学人员提供成长、 发展和贡献的机会; 7、最大限度利用学校的各种资源。 同样, 学术组提出了 8 项学术规划建议 [2]。

\section{4 战略管理第四步：制定实施策略}

在提出管理规划和学术规划之后, 进入了战略实施阶 段。明大依然组建了学术、管理两支队伍: 包括7个管理 实施战略组, 27 个学术实施战略组, 负责根据规划原则, 把战略建议变成行动项目。项目书包括: 项目、理由、内 容、与其他项目的关系、负责人、资助者、时限、评估内 容及方式等。例如, 管理服务与生产力规划小组提出了 104 个行动项目。其中, “统一观念” 方面 17 个, “管理 文化” 方面 8 个, “管理模式” 方面 16 个, “管理工具” 方面 16 个, “服务意识” 方面 20 个。项目书的形成是战略 规划的转折点, 这意味着把设想变成行动。

\section{5 战略管理结果}

战略规划两年后, 学校本科生申请率提升了 $40.6 \%$; 两年内新增了 426 名教师 (当时的目标是五年内增加 1000 名教师）。学术创新方面新增加了 3.58 亿美元财政预算, 其中本科生科研项目、研究生经济资助、跨学科科研机构 有了很大进展, 明大在Rochester地区成立了新的校区。学 校再次看到了成为世界一流大学的希望 [3]。

\section{3. 明尼苏达大学发展战略规划给予的启示}

\section{1 重视对环境的扫描}

明大环境扫描分社会、政治、经济环境、学校竞争环 境、财务环境四大领域, 对学校所处的环境、优势和挑战 分析十分清晰深透。摸清了学校的家底, 找出了优势和劣 势, 确立了发展的战略思想, 寻求战略规划真正与实际工 作结合的连接点 $[4]$ 。

3.2 科学定位, 发展目标强调现实性和可能性 
一是志存高远, 用总体目标指引和激励大学前行, 总 体目标是大学发展的终极旨归。二是用具体目标为总体目 标提供有力支撑, 具体目标是大学所选择的重点发展的若 干项目及领域, 它涉及发展规模、学科专业、科学研究、 师资队伍、基本设施、经费投入等 $[4]$ 。

\section{3 立足本校，规划重点具特色性}

明大一是强调战略规划的落脚点是本校而非他校; 二 是强调战略规划是学校的规划而非个人的规划。也就是 说, 学校战略规划要注重对本校特色的识别、传承和创 造。明大列出七条标准、五个重点发展战略都立足于本校 的传统与特色, 强调解决学校发展过程中亟需解决的问 题。

3.4 领导决策, 分工明确, 两条线路通力合作
在校长布鲁宁克斯宣布开启学校新的战略规划之后, 整个战略规划制定工作分成管理和学术两个基本方面。大 学所有副校长、各主要部门负责人及部分教师和学生参加 了这两个小组, 确保了两条线各司其职, 有效率地攻克了 战略规划过程中的不同的难题。

\section{5 严格规划, 规划过程重视逻辑性和连贯性}

第一, 明大在发展规划里, 含有长期目标行动计划、 短期具体举措以及规划实施的进展监控报告等。它将学校 的战略目标分解成有针对性的、可操作的、可测量的目标 和任务, 而且要求校内学术战略组和管理战略组结合学校 规划和常规工作制订自己的实施计划。第二, 在明确规划 思路和方案之后, 明大每项措施都针对解决一个具体问 题。第三，明大针对战略发展规划，制定了投资战略规 划, 提供强有力的财政支持与物质保证等, 确保了规划过 程的连贯有效。

明大战略规划的逻辑过程可以通过图一反映出来:

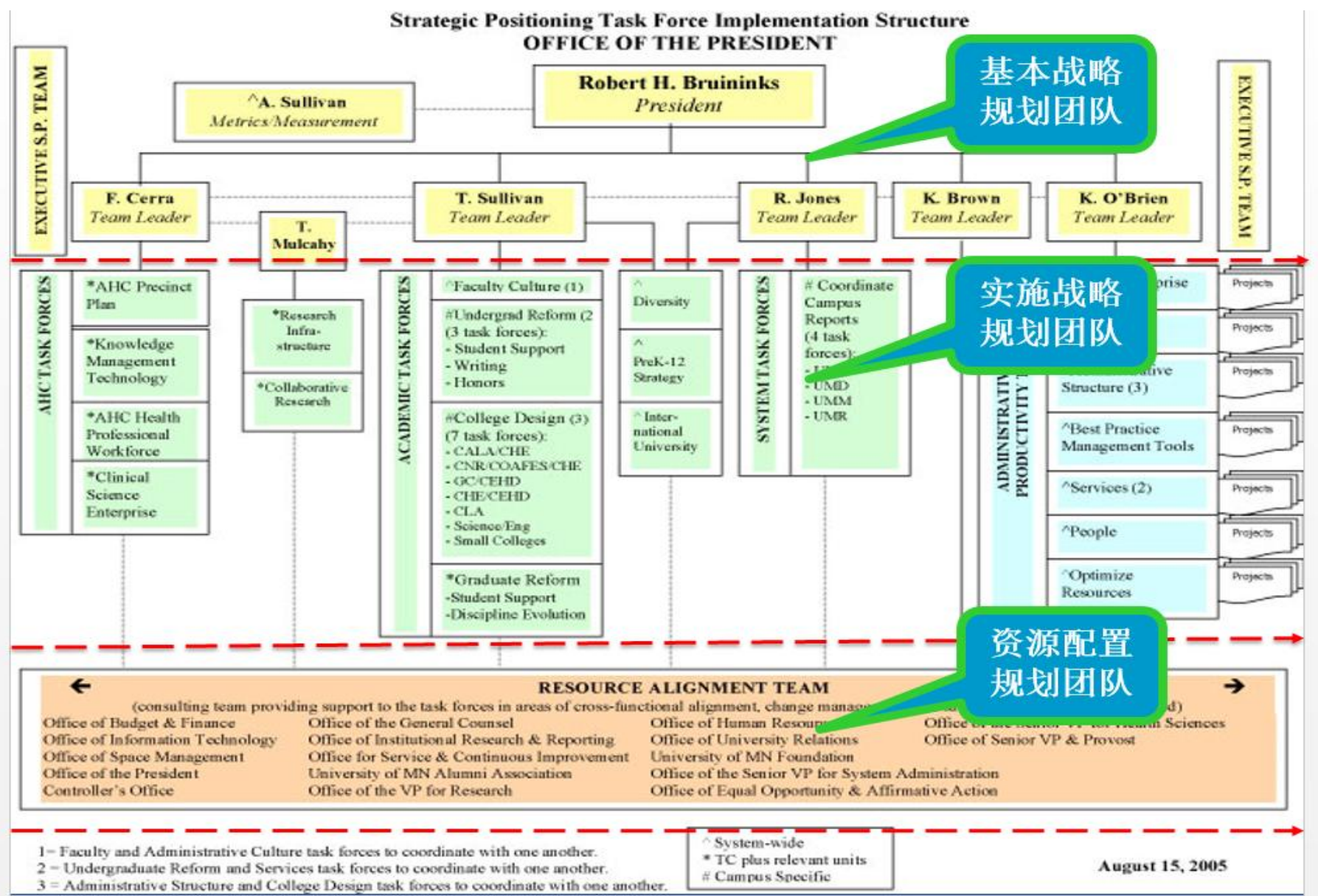

图一：明尼苏达大学战略规划逻辑关系图 [2] 


\section{4. 河海大学综合改革方案的编制}

河海大学是一所有近百年办学历史, 以水利为特色, 工科为主, 多学科协调发展的教育部直属全国重点大学, 是实施国家 “211工程” 重点建设、“985工程优势学科创 新平台”建设的公立研究型大学。

2014年9月, 应教育部要求及河海大学自身发展的迫 切需要, 河海大学开始了综合改革方案的制定工作。与明 大类似, 河海大学也是一所公立研究型大学, 同样担负着 着本科、研究生教育和学术研究的重任, 在发展过程中也 遇到了亟需解决的问题。河海大学在综合改革方案制定 时, 尝试采用了明大策略制定的方法。以下将河海大学综 合改革方案制定过程进行分析。

\section{1 综合改革环境扫描}

河海大学在制定综合改革方案初期, 就成立了综合改 革领导小组以及工作小组, 作为统领整个改革过程的战略 规划团队。这两支团队对学校综合改革的社会、政治、经 济环境、学校竞争环境、财务环境四大领域进行了扫描和 分析, 查找了自身存在的差距和问题, 得出以下结论:

其中, 宏观环境方面:

1、党的十八大报告提出 “深化教育领域综合改革” 的总体要求。2、当前, 高等教育进入新的发展阶段, 学 校软环境建设受到更多的制约, 不改革, 不突破, 就很难 摆脱当前相对封闭、粗放、资源投入型的发展模式。3、 近些年学校在开展行业重大问题与重大项目的研究上表现 出一定的不足, 办学特色以及国内外认可程度不高。

竞争环境方面: 1、近些年毕业生进入行业各级管理 岗位就业的机会减少, 对扩大学校在行业内的影响力不 利。2、学科布局中水利学科一枝独秀, 高峰学科略显单 薄。3、河海大学参与重大水利问题研究的机会减少, 要 强化与水利行业的密切联系。

内部环境方面: 1、学校学科面窄, 迫切需要从传统 水利向现代水利, 从水利向水, 从河向海进行学科延伸。 2、由于从事水利科研教学工作的人员数量较多, 绩效考 核还不到位，教师和行政人员的积极性不高。

财务环境方面: 学校的办学资源来源单一、不够充 裕。学校无论是在资金筹措和土地利用等资源获取方面, 均存在办学资源不充足、办学资源来源单一的问题。

\section{2 制定综合改革方案框架}

战略框架由学校的综合改革领导小组和综合改革小组 共同制定。这一过程分三个阶段完成。

4.2.1 分析学校的目标、愿景、使命

河海大学制定了自身的发展目标: 第一步, 形成高水 平特色研究型大学格局, 水利学科在国际上具有广泛影 响; 第二步, 到2020年前后, 建成高水平特色研究型大 学, 水利学科国际一流。愿景是: “水利特色, 世界一 流”。使命是：以为国家培养高素质创新型人才为己任,
以探索真理、服务国家、造福人类、引领科学技术进步为 使命。

\subsection{2 确定综合改革战略规划原则}

1）以教育部明确的综合改革六大领域为重点；2）以 河海大学核心使命及目标为中心；3）注重改革的质量、 产能、影响；4）立足学校作为行业性研究型大学的优势 与独特性；5）注重政策诉求与资源的协调；6）强调措施 的效果与效益。

\subsection{3 明确规划的重点领域}

与明大相同, 河海大学战略规划的落脚点是本校, 注 重了对本校特色的识别、传承和创造。改革重点领域最终 被确定为四个方面: 人事制度, 现代大学治理, 专业建 设, 改革特区。改革的重心被归纳为 “一个主驱, 三个副 驱, 四轮驱动, 带动全面” [5]。

“一个主驱” 是指: 以人事与分配制度改革为主驱, 结合人事分类评价, 科研分类评价, 教学分类评价体系的 构建, 形成强大的驱动能量。“三个副驱” 是指: 以现代 大学治理、专业建设、改革特区为三个副驱。“带动全 面” 是指: 通过核心领域的改革和突破, 带动学校在人才 培养、科学研究、社会服务、文化传承与创新方面的全面 发展。

\section{3 确定综合改革方案规划}

与明大相似, 河海大学把整个战略规划制定工作分成 管理和学术两大基本方面。其中, 职能部门领导、民主党 派代表、党委常委成员组成了规划的管理团队, 主要负责 人事制度、内部治理、国际化方面政策的规划; 各学院领 导、学生与教师代表组成了规划的学术团队, 主要在人才 培养、科学研究、服务社会等方向的策略进行规划。

管理、学术团队共谋共议, 最终确定了六大领域 34 条 改革措施以及 6 条思想、组织、财务方面的保障措施。在 制定战略任务时, 河海大学尽量立足本校特色与需求, 确 保战略规划的逻辑性和特色性。（图二为河海大学综合改 革方案编制逻辑关系图)。

\section{4 制定实施规划}

河海大学 22 个职能部门、 6 个直属单位、 16 各院系根 据规划原则, 把战略任务变成行动项目, 完成对战略任务 的细化，提交改革举措项目书。项目书包括：改革项目、 项目内容、改革背景、改革举措、改革进程、风险评估、 审批程序等。学校尽量确保规划的科学性和连贯性, 将学 校的战略目标分解成有针对性的、可操作的、可测量的目 标和任务, 并要求相应部门结合学校规划和常规工作制订 本部门年度、学期计划。

例如: 在 “以改革特区为抓手，改革科研体制机制” 这一改革任务中, 河海大学科技处、协同创新中心办公 室、国家重点实验室、水利水电学院、水文水资源学院、 港口海岸与近海工程学院、环境学院等学院共同提交了 12 条具体的改革建议, 最终被管理团队、学术团队经商议精 
简为 5 条可实施的任务举措：建立改革特区; 加大科技平 台建设, 促进重点学科发展; 繁荣人文社会科学发展, 提 升学校综合实力, 改革技术转移和成果转化模式; 建立科 技分类评价制度 $[5]$ 。

其中, “建立改革特区” 这一条建议立足于学校的目 标、愿景、使命, 坚持了战略规划原则, 着眼于形成与行 业、流域联合体制的研究平台, 推动成果转化, 最终提升 河海大学服务社会的能力。这项举措从改革措施、改革进 程、风险评估和审批程序等方面详细指出了任务实施部门
2015年的短期任务和直至2020年的长期任务指标, 保证了 措施的针对性和有效性。

\section{5 综合改革方案制定成果}

在校领导指导、各团队通力合作下, 经过对综合改革 方案初稿、征求意见稿以及最终稿的多轮讨论和反复修 改, 河海大学最终按计划于 2015 年完成综合改革方案的撰 写, 2015年5月, 《河海大学综合改革方案》顺利通过教 育部审批。

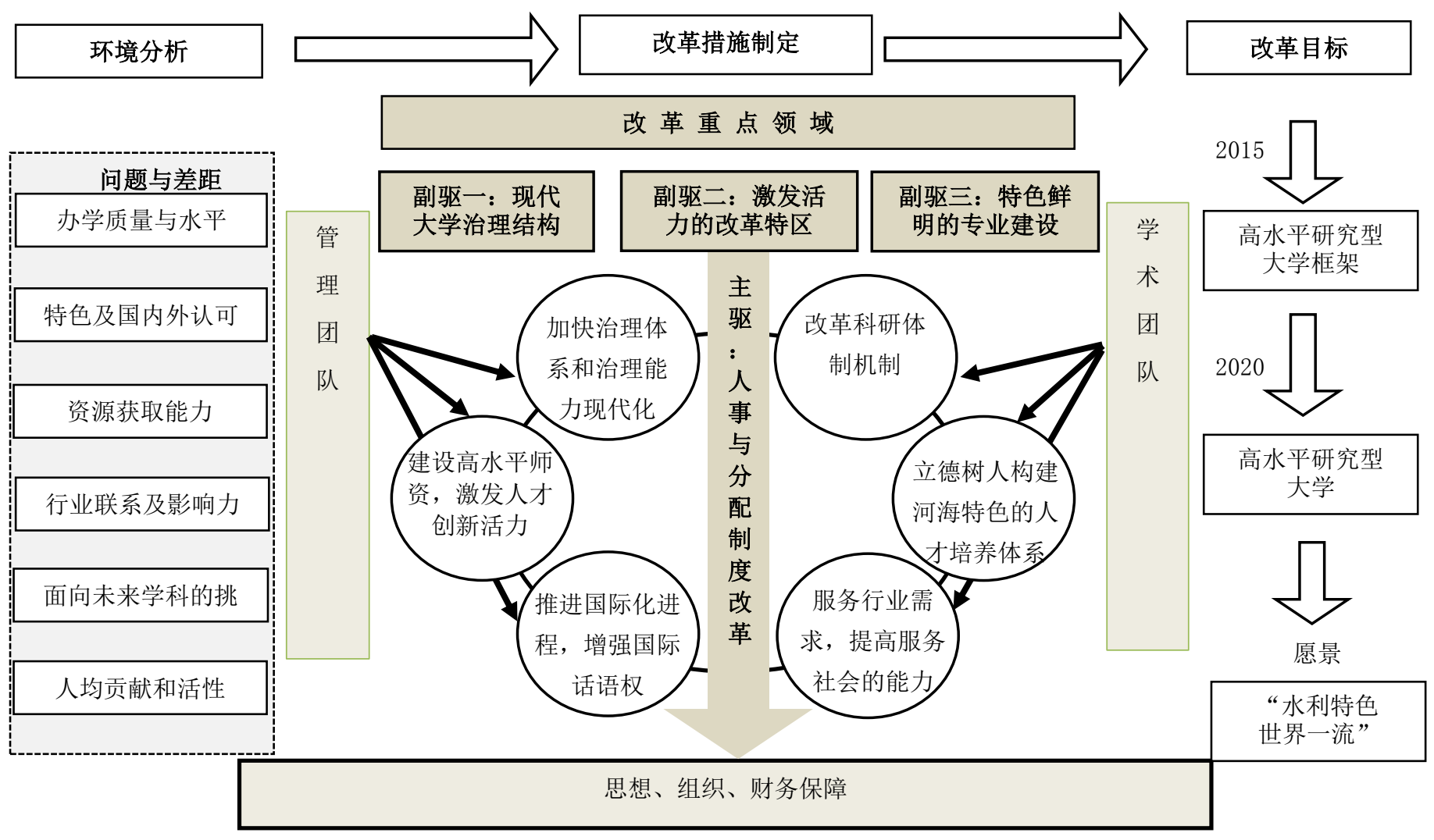

图二：河海大学综合改革方案编制逻辑关系图

\section{5. 结语}

美国高校战略规划起步较早, 积累了丰富的实践经 验, 我国高校的战略规划工作相比较还存在着一定的差 距。本文通过对美国明尼苏达大学战略规划制定的分析, 总结其逻辑思路、特点特色及成功经验, 并尝试性地将其 运用于河海大学综合改革方案制定过程中, 通过构建综合 改革方案逻辑关系图将战略规划策略应用于实践。虽然此 次尝试并非十分成熟, 综合改革方案的最终实施效果也需 要后续跟进, 但希望此举能为提高我国高校战略规划提供 一定思路和借鉴。

\section{参考文献(References)}

[1] Karen E. Hinton, a practical guide to strategic planning in higher education, society for college and university planning, 2012.7.

[2] Zhao Juming, How to Construct Top Universities in America, 2015.

[3] Administrative Strategic Planning Task Force. Report to the President[EB/OL].www.umn.edu.

[4] Zhang Wangfa, Strategic Planning and Inspirations of Three American Universities. Journal of Adult Education in Northwest China, 2010.5.

[5] Comprehensive Reformation Program in Hohai University, 2010. 